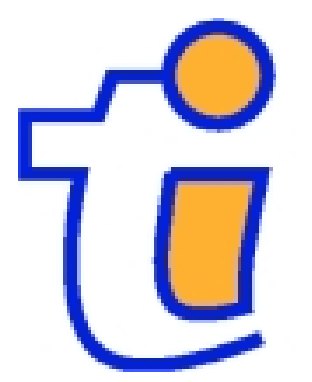

TI 2001-009/4

Tinbergen Institute Discussion Paper

Stock Selection Strategies in Emerging Markets

Jaap van der Hart

Erica Slagter

Dick van Dijk 


\section{Tinbergen I nstitute}

The Tinbergen Institute is the institute for economic research of the Erasmus Universiteit Rotterdam, Universiteit van Amsterdam and

Vrije Universiteit Amsterdam.

\section{Tinbergen I nstitute Amsterdam}

Keizersgracht 482

1017 EG Amsterdam

The Netherlands

Tel.: +31.(0)20.5513500

Fax: $\quad+31 .(0) 20.5513555$

\section{Tinbergen I nstitute Rotterdam}

Burg. Oudlaan 50

3062 PA Rotterdam

The Netherlands

Tel.: +31.(0) 10.4088900

Fax: $\quad+31 .(0) 10.4089031$

Most TI discussion papers can be downloaded at http://www.tinbergen.nl 


\title{
Stock Selection Strategies in Emerging Markets*
}

\author{
Jaap van der Hart $^{\dagger}$ \\ Emerging Markets Team \\ Robeco Group
}

\author{
Erica Slagter ${ }^{\ddagger}$ \\ Department of Quantitative Research \\ Robeco Group
}

\author{
Dick van Dijk ${ }^{\S}$ \\ Econometric Insitute \\ Erasmus University Rotterdam
}

December 2000

\begin{abstract}
Recent empirical evidence suggests that value and momentum strategies generate significant excess returns in emerging markets. We confirm these results and extend them in several directions. First, we examine a broader range of stock selection strategies, including strategies based on analysts' earnings revisions. We also consider multivariate strategies, whereby stocks are selected on multiple characteristics, and find that this enhances the overall performance. Excess returns also increase if country selection is incorporated into the strategies, but the risk of the strategies increases proportionally. Second, we test whether the strategies can be implemented successfully in practice by a large institutional investor, facing a lack of liquidity, restrictions on foreign ownership and substantial transaction costs. We find that even under such more realistic circumstances the strategies earn significant excess returns. Third, we examine several popular explanations for the excess returns. We find no evidence of higher market risk or lower liquidity of the strategies. Instead, based on the developments of earnings and earnings revisions after portfolio formation, we find that the results are consistent with behavioral explanations.
\end{abstract}

Keywords: value, momentum, earnings revisions, market imperfections, risk, behavioral models, overreaction, underreaction.

JEL Classification: G11, G15

*We thank Angelien Kemna and Ronald Wuijster for useful comments and suggestions. Any remaining errors are ours.

${ }^{\dagger}$ Robeco Group, P.O. Box 973, 3000 AZ, Rotterdam The Netherlands, email: j.m.van.der.hart@robeco.nl

${ }^{\ddagger}$ Robeco Group, P.O. Box 973, 3000 AZ, Rotterdam The Netherlands, email: e.j.slagter@robeco.nl

$\S$ Econometric Institute, Erasmus University Rotterdam, P.O. Box 1738, NL-3000 DR Rotterdam, The Netherlands, email: djvandijk@few.eur.nl (corresponding author) 


\section{Introduction}

The success of quantitative stock selection strategies in developed markets is well documented. Portfolios formed on the basis of earnings-to-price (E/P), book-tomarket $(\mathrm{B} / \mathrm{M})$, price momentum or earnings revisions have been found to earn significant excess returns across developed markets. ${ }^{1}$ For emerging markets, however, only few studies exist that investigate individual stock selection, which, moreover, have rendered conflicting results. For example, whereas Claessens, Dasgupta and Glen (1998) find evidence for a premium for large firms and growth stocks, Fama and French (1998), Patel (1998) and Rouwenhorst (1999) report a premium for small firms and value stocks. Claessens et al. (1998) also document a premium for beta and turnover, but Rouwenhorst (1999) finds no evidence for either of those. Whereas the aforementioned studies considered only a limited number of strategies, Achour et al. (1998) examine a much broader range of trading strategies based on firm characteristics, but their sample includes only stocks from 3 emerging markets (Malaysia, Mexico and South Africa).

In this paper, we further examine the performance of stock selection strategies for emerging markets. Compared to the above-mentioned studies, we consider both a more extensive set of strategies and a larger sample of stocks. Besides value and momentum strategies, we also include strategies based on short term and long term mean reversion, earnings revisions by analysts, size and liquidity. We also consider multivariate strategies, which rank stocks according to indicators of value, momentum and earnings revisions jointly. Finally, we compare local and global selection strategies, and thus contrast the profits that arise from stock selection within countries with those from country selection. All strategies are evaluated on a sample consisting of stocks from all emerging markets.

Our results can be summarized as follows. Using internationally diversified (but country-neutral) portfolios, we find that high E/P and B/M ("value") stocks outperform low E/P and B/M ("growth") stocks, and stocks with positive analysts' earnings revisions outperform stocks with negative revisions. The success of momentum strategies depends on the type of investment strategy that is used. A conventional "zero-cost" strategy, consisting of a long position in a winners portfolio

\footnotetext{
${ }^{1}$ Most studies in this area have concentrated on US stocks. A non-exhaustive list of studies which consider data from international developed equity markets includes Capaul, Rowley and Sharpe (1993), Haugen and Baker (1996), Arshanapalli, Coggin, and Doukas (1998), Bauman, Conover and Miller (1998, 1999), Fama and French (1998), Rouwenhorst (1998) and Baytas and Cakici (1999).
} 
and an off-setting short position in a losers portfolio, generates significant excess returns. The average return from a strategy consisting of a long position in the winners portfolio only, however, is not significantly different from the return on an equally weighted portfolio of all stocks. We find no evidence for short term or long term mean reversion, nor do we find that returns are systematically related to size or liquidity. Combining value, momentum and earnings revisions indicators into a multivariate strategy improves the overall performance. The results for individual countries are much less positive than for internationally diversified portfolios, which shows that these strategies can be best applied in all emerging markets simultaneously. Finally, stock selection and country selection contribute about equally to the returns from global stock selection strategies.

The excess returns of the stock selection strategies are based on the implicit assumption of perfect capital markets. A natural question to ask is whether these strategies are still profitable if applied in practice by a large investor. Market imperfections relevant in emerging markets that may prevent successful implementation are lack of liquidity, restrictions on foreign ownership, outliers, and transaction costs. We address this issue by evaluating the selection strategies under different circumstances, accounting for each of these imperfections in turn. We find that the excess returns of the best performing strategies remain significant when the sample is restricted to stocks with the largest market capitalizations or to stocks which are available to foreign investors only, after correcting for outliers, and after taking into account transaction costs.

Another important question that we address is the source and interpretation of the excess returns. We find no evidence of higher market risk or lower liquidity for the strategies. Instead, the results are consistent with behavioral explanations, both for the value strategies and for the momentum and revisions strategies.

Lakonishok, Shleifer and Vishny (1994) provide evidence for the US that the excess returns of value strategies are due to too large differences in valuation ratios for glamour versus value stocks. They demonstrate that the implied growth rates in, for example, earnings are not justified by later developments. After the first couple of years after portfolio formation, growth rates are the same for value and glamour stocks. Our results for emerging markets are consistent with this explanation. Although earnings growth is smaller for value stocks in the first year after portfolio formation, after about two years it has returned to the average level for all stocks.

Chan, Jegadeesh and Lakonishok (1996) provide evidence for the US that the 
excess returns of revisions and momentum strategies are due to a market reaction to new information. They demonstrate that stocks with high past earnings revisions or high price momentum have higher returns around earnings announcements, higher earnings revisions and higher earnings surprises for some time after portfolio formation. We find the same for emerging markets. During the first year after portfolio formation, stocks with large positive earnings revisions or high momentum have more upward revisions by analysts than the average stock.

The plan of this paper is as follows. Section 2 describes the data and stock selection strategies, and Section 3 documents their profitability. Section 4 examines how much of the excess returns on the trading strategies is left after taking into account various market imperfections. Section 5 explores different explanations for the excess returns of the strategies. Finally, Section 6 concludes.

\section{Methodology}

\section{$2.1 \quad$ Data}

Stock prices and relevant firm characteristics are taken from the Emerging Markets (EM) database of the International Finance Corporation (IFC). Monthly total returns in US dollars are calculated using stock prices, dividends and capital adjustment factors, cf. Rouwenhorst (1999). Some apparent data errors due to wrongly calculated stock split ratios were corrected. The firm characteristics that we use are total earnings, book value, dividends, number of shares traded and number of outstanding shares. The sample period runs from January 1982 until May 1999. As one of our selection strategies requires 3 years of past returns data, we consider portfolios formed every month starting at the beginning of January 1985.

At the end of our sample period, the EM database contains data on 2851 firms from 32 emerging markets. Not all of these are included in our sample, however, for several reasons. First, the IFC database contains survivorship bias, as data (returns in particular) are backfilled when IFC starts constructing data for new countries. We avoid this survivorship bias by using at any time only stocks from countries that are included in the IFC Composite index, cf. Fama and French (1998) and Rouwenhorst (1999). See Harvey (1995) for a detailed discussion of this feature of the EM database. Second, we omit countries with less than four stocks and countries for which the data necessary for the particular selection strategy is available for less than 30 percent of the stocks. We omit these "small" countries because the selection 
strategies construct local return factor portfolios from the top and bottom 15 percent stocks in each country separately. Finally, we avoid stocks that are too small for large institutional investors, by including only stocks with market capitalization in excess of 100 million US dollars in December 1998, which is deflated with 10 percent annually. ${ }^{2}$ This also alleviates potential problems of survivorship bias and low-priced stocks. The above restrictions leave us with a sample or "universe" of about 200 stocks in 10 countries in January 1985, gradually expanding to approximately 1200 stocks in 32 countries in May 1999.

The data from the IFC EM database are supplemented with data on analysts' earnings forecasts from the Institutional Brokers Estimate System (IBES). This database contains data on firms in emerging markets starting in January 1987. The earnings forecasts are used to calculate "forward" earnings-to-price ratios as the ratio of the median earnings forecast and the current stock price, and earnings revisions. We do not use the changes in analysts' earnings forecasts directly but instead define earnings revisions as the number of analysts with upward revisions minus the number of analysts with downward revisions, divided by the total number of analysts providing an earnings forecast in a particular month. As analyst coverage was rather low initially, we consider portfolios formed on the basis of forward earnings-to-price ratios and earnings revisions from the beginning of May 1988 onwards.

\subsection{Stock Selection Strategies}

We test several stock selection strategies based on indicators of value, momentum, earnings revisions, size and liquidity. As measures of value we use the earnings-toprice ratio $(\mathrm{E} / \mathrm{P})$, the book-to-market ratio $(\mathrm{B} / \mathrm{M})$, the dividend yield $(\mathrm{D} / \mathrm{P})$, and the forward $\mathrm{E} / \mathrm{P}$ ratios for the current fiscal year (E/P FY1) and for the next fiscal year (E/P FY2). For the momentum strategies, we use the average return over the past 1, 3, 6, 9, 12 and 36 months (denoted as $k \mathrm{MR}$, with $k$ the number of months). Earnings revisions are measured by the past 3-month average earnings revisions for the current fiscal year (ER FY1) and for the next fiscal year (ER FY2). Size is taken to be the market capitalization of the stock at the beginning of the month. Finally, we follow Rouwenhorst (1999) in measuring liquidity by the turnover ratio, defined as the number of shares traded during the previous month divided by the total number of outstanding shares at the beginning of the month.

\footnotetext{
${ }^{2}$ The EM database itself already contains a selection bias towards larger stocks, as market capitalization is one of the criteria used by the IFC to select stocks for its indices.
} 
At the beginning of each month, we rank the stocks by country on each of the above characteristics or "return factors" in descending order. The rankings based on the past 1- and 36-month return variables are in ascending order, such that we effectively test short term and long term mean reversion, cf. Jegadeesh (1990) and Lehmann (1990), and De Bondt and Thaler (1985, 1987), respectively. The rankings based on size and liquidity also are in ascending order, such that the smallest stocks and stocks with the lowest turnover ratio, respectively, are the top ranked ones. For each country in the sample, an equally weighted portfolio is formed from the top 15 percent ranked stocks or "winners". These country portfolios are in turn combined with equal weights into an internationally diversified portfolio. The stocks are selected in each country separately to avoid any implicit country allocation, but we return to this point in Section 3.4. Each month, a new portfolio is constructed which is held for a period of 6 months. After formation, the portfolio is not rebalanced, except for stocks that leave the IFC-index. These stocks exit the portfolio and the weights of the remaining stocks are adjusted proportionally.

As we construct new portfolios every month and use a six-month holding period, at any point in time the strategies effectively hold, for example, six portfolios of the top 15 percent stocks, each formed one month apart. To handle the problems concerned with overlapping returns, we calculate monthly returns as the average of the six portfolios, cf. Jegadeesh and Titman (1993), and compute standard errors using the Newey-West correction for heteroskedasticity and autocorrelation (up to order 5).

The performance of stock selection strategies is usually measured as the return on a "zero-investment" strategy, involving a long position in a "winners" portfolio and an off-setting short position in a "losers" portfolio, as in Fama and French (1998) and Rouwenhorst (1999), among many others. However, it might be questioned whether these returns can actually be realized in practice, as short-selling constraints may prevent implementation of such a zero-investment strategy, see Alexander (2000) for discussion. Short-selling restrictions are particularly relevant for emerging markets, see Bekaert and Urias $(1996,1999)$ and de Roon, Nijman and Werker (2001). ${ }^{3}$ For this reason, we primarily compare the average return of the winners portfolio with

\footnotetext{
${ }^{3}$ In addition to short-selling constraints, restrictions on foreign ownership and other capital controls in emerging markets may be important barriers to effective implementation of the stock selection strategies considered here, see Bekaert (1995). We address this point to some extent in Section 4 , where we evaluate the performance of the strategies using only stocks included in the IFC Investables index.
} 
an equally weighted index (EWI) consisting of all stocks in the relevant universe. To facilitate comparison of our results with those of Fama and French (1998) and Rouwenhorst (1999), we also provide some results on a zero-cost strategy, by computing the excess return of the winners portfolio over an equally weighted losers portfolio constructed from the bottom 15 percent ranked stocks in each country. Also, as noted by Achour et al. (1998), even if the losers portfolio can not be used in a trading strategy, it still provides important information regarding which stocks are to be avoided.

\section{$3 \quad$ Profitability of Stock Selection Strategies}

In this section, we evaluate the performance of the various stock selection strategies. We consider results for "univariate" strategies which rank stocks according to a single return factor, and for "multivariate" strategies which combine measures of value, momentum and/or earnings revisions to produce the stock ranking. We also present results for individual countries and geographic regions, showing that most strategies are not successful on such smaller samples of stocks. Finally, we examine the benefits from using the strategies for country selection in addition to stock selection.

\subsection{Univariate Strategies}

Table 1 summarizes the average monthly returns during the six-month holding period for the winners portfolio, the equally weighted index and the losers portfolio formed on the basis of a single return factor. Of the different value strategies considered, the earnings-to-price strategy generates the highest average excess return. This holds irrespective of whether excess returns are measured relative to the equally weighted index or relative to the losers portfolio. The average return on the $\mathrm{E} / \mathrm{P}$ portfolio exceeds the return on the EWI benchmark by 0.53 percent per month, whereas high $\mathrm{E} / \mathrm{P}$ stocks have outperformed low $\mathrm{E} / \mathrm{P}$ stocks by 1.02 percent per month. These excess returns are strongly statistically significant, with $t$-statistics of 4.45 and 5.46 , respectively. Excess returns from the B/M strategy are only slightly lower, and close to the average excess returns reported by Rouwenhorst (1999). Selecting stocks based on their dividend yields in the previous month does not generate significant excess returns relative to the EWI. However, because the average return of the portfolio of stocks with very low dividend yields is much smaller than the average benchmark 
return, the return of the top minus bottom (TMB) portfolio is significant, albeit it is only half as large as the excess returns based on the $\mathrm{E} / \mathrm{P}$ and $\mathrm{B} / \mathrm{M}$ strategies. The strategies based on forward $\mathrm{E} / \mathrm{P}$ ratios also generate modest excess returns, but these are not significantly different from zero.

\section{- insert Table 1 about here -}

The results from the momentum strategies based on past 3-, 6-, 9- and 12-month returns are very similar. The winners portfolios from these strategies have excess returns between 0.1 and 0.2 percent per month versus the EWI, which are not statistically significant. Excess returns are larger for the TMB portfolios, between 0.4 and 0.5 percent per month, and are statistically significantly different from zero. The profitability of the TMB portfolio is, however, mainly due to underperformance of the losers portfolio, as the returns on the losers portfolios are much smaller than the returns on the EWI. Consequently, the profits from a "zero-investment" strategy based on the TMB portfolio would mostly come from the sell side of the strategy. Because of short sales restrictions in emerging markets, it is questionable whether these returns can be realized in practice.

The average excess return of the TMB portfolio based on prior 6-month returns is similar to the excess return reported by Rouwenhorst (1999), even though his winners and losers portfolios include stocks from the top and bottom 30 percent of the prior return distribution. ${ }^{4}$ The momentum returns in emerging markets found here are notably smaller than returns of comparable momentum portfolios for developed markets reported in Jegadeesh and Titman (1993) and Rouwenhorst (1998), which average approximately 1 percent per month. Admittedly, in these studies the winners and losers portfolios contain only stocks from the top and bottom 10 percent of the prior return distributions compared to 15 percent in our strategies, but it is difficult to imagine that this small difference in methodology can explain the large difference in excess returns completely.

The excess returns of strategies based on short term and long term mean reversion (1MR and 36MR, respectively), size and liquidity do not differ substantially from zero. In fact, the returns of smaller and less liquid stocks are somewhat lower than the returns of larger and more liquid stocks, although the differences are not

\footnotetext{
${ }^{4}$ The fact that excess returns nevertheless are of similar magnitude might (partly) be due to the fact that the cross-sectional return distributions in emerging markets are far from normal and in particular have much fatter tails, as documented in Bekaert et al. (1998).
} 
significant. Our findings for the liquidity strategy are similar to Rouwenhorst (1999), but the results for the size strategy are quite different from Fama and French (1998), Patel (1998) and Rouwenhorst (1999), who report evidence for a premium for small firms in emerging markets. This difference with our results can be attributed to differences in methodology, such as different universes of stocks and different holding periods.

Finally, the strategies based on analysts' earnings revisions prove to be quite successful. Relative to the EWI, the ER portfolios generate statistically significant excess returns of 0.3 percent per month, irrespective of whether revisions for the current or for the next fiscal year are used. The excess returns for the top minus bottom portfolios also are strongly significant and equal about 0.6 percent per month, which is only slightly smaller than the most successful value strategies based on $\mathrm{E} / \mathrm{P}$ and $\mathrm{B} / \mathrm{M}$. Our results concerning the usefulness of earnings revisions for emerging markets confirm the findings of Achour et al. (1998) for the much larger set of emerging markets considered here.

The performance of the strategies based on E/P, B/M, 6-month momentum (6MR), and earnings revisions for the current fiscal year (ER FY1) over time are shown in Figure 1, which plots the cumulative outperformance of the winners portfolios relative to the EWI (January 1985=100). For three of these four strategies, the performance improves considerably over time. Over the period from January 1985 until December 1990, the average excess returns from the B/M, 6MR, and ER FY1 strategies are equal to $0.41,-0.03$ and 0.02 percent per month, respectively, which increase to $0.55,0.27$ and 0.40 percent per month over the period January 1991-May 1999. Notably, this is not the case for the E/P strategy, for which the excess return is equal to 0.53 percent per month in both sub-periods. The change in excess returns from the B/M, 6MR and ER FY1 strategies might be related to capital market liberalizations and structural reforms in emerging equity markets, which in most countries took place during the late 1980s and early 1990s. See Bekaert (1995) and Bekaert and Harvey (2000a) for detailed accounts and Bekaert and Harvey (2000b) and Henry (2000) for investigations into the effects of these reforms. Our results deviate from Bekaert et al. (1997, 1998), who find that mean returns in many emerging market countries were lower and the same, respectively, in the 1990s compared to the 1980 s.

- insert Figure 1 about here - 
Finally, the $\mathrm{E} / \mathrm{P}$ and $\mathrm{B} / \mathrm{M}$ strategies were clearly affected by the Asia crisis in 1997-98 during which they underperformed relative to the EWI, although by 1999 the cumulative returns from these strategies had rebounced to pre-crisis level. By contrast, the performance of the earnings revisions strategy did not deteriorate during this period.

\subsection{Multivariate Strategies}

Ranking firms on a single indicator can easily lead to misclassification of stocks. For example, value stocks with temporarily depressed earnings that might be expected to recover quickly can nevertheless drop out of the winners portfolio or even be assigned to the losers portfolio if firms are ranked on E/P only. Following Lakonishok et al. (1994) and Chan et al. (1996), we therefore consider multivariate strategies which rank stocks on multiple indicators. However, our methodology differs slightly from these studies, which combine independent rankings based on two factors.

We consider strategies based on value, momentum and revisions variables. The selected indicators are $\mathrm{E} / \mathrm{P}$ and $\mathrm{B} / \mathrm{M}$ (value), past 6- and 12-month returns (momentum), and earnings revisions for the current and next fiscal year (revisions). These variables are among the best performing univariate strategies, as shown in Table 1. All variables are normalized by subtracting the median and dividing by the cross-sectional median absolute deviation. We use the median and median absolute deviation instead of the mean and standard deviation to limit the influence of outliers. The effect of outliers is further reduced by trimming the normalized variables at values of plus and minus 3. The score for the combined strategy then is obtained as the sum of the relevant normalized variables. For example, to obtain the score of a stock for the "value and momentum" strategy, we add the normalized values for $\mathrm{E} / \mathrm{P}, \mathrm{B} / \mathrm{M}$ and 6 - and 12-month returns. Based on the ranking according to this overall score, the top and bottom 15 percent of stocks are combined into equally weighted winners and losers portfolios, as in the univariate strategies.

Table 2 summarizes the results of the multivariate strategies. It is seen that combining different characteristics leads to higher (excess) returns in all cases. The winners portfolio of the strategy based on value and revisions (VR) generates the highest average excess returns, equal to 0.62 and 1.31 percent per month relative to the EWI and the losers portfolio, respectively. Adding momentum to this strategy lowers these excess returns slightly, to 0.56 and 1.19 percent per month. However, because the volatility of the excess returns also decreases, the corresponding $t$-statistics 
are actually higher than for the VR strategy. A possible explanation for this effect is the negative correlation between the excess return of the momentum strategy and the excess returns of the value and earnings revisions strategies, which are equal to -0.32 and -0.20 , respectively. ${ }^{5}$

\section{- insert Table 2 about here -}

The cumulative outperformance of the multivariate VMR strategy is shown in Figure 1. The excess return is approximately constant over time (equal to 0.55 and 0.57 percent per month during the pre- and post-1991 periods), which obviously is due to the inclusion of $\mathrm{E} / \mathrm{P}$ as one of the characteristics. Note that the cumulative profits remained roughly stable during the last two years of the sample period. Apparently, the negative performance of the value characteristics canceled out against the positive performance of the earnings revisions during the Asia crisis.

\subsection{Profitability by Country and Region}

The results presented so far concern internationally diversified portfolios. Table 3 summarizes the excess returns of the winners portfolios in the $\mathrm{E} / \mathrm{P}, \mathrm{B} / \mathrm{M}, 6 \mathrm{MR}, \mathrm{ER}$ FY1 and VMR strategies for the individual countries in our sample. Excess returns in this case are measured relative to the local equally weighted index. Note that these strategies were the most successful ones for the international portfolio.

For the univariate strategies, only few countries have significant positive excess returns. In fact, for the $\mathrm{B} / \mathrm{M}$ and $6 \mathrm{MR}$ strategies excess returns actually are negative for almost half of the countries. The results do not improve notably for the multivariate VMR strategy. Our findings again correspond with Rouwenhorst (1999), who finds very few significant excess returns of winners minus losers portfolios for individual countries for different value and momentum strategies.

\section{- insert Table 3 about here -}

The combined results in Tables 1-3 clearly demonstrate the benefits from international diversification for investing in emerging markets. The small number of stocks in most countries together with the high volatility of returns prevent successful implementation of the stock selection strategies in individual markets. Because of the

\footnotetext{
${ }^{5}$ The correlation between the excess returns of the value and revisions strategies is equal to 0.22 .
} 
(unreported) low correlations between the (excess) returns in different countries, applying the trading strategies globally reduces portfolio risk considerably, such that significant excess returns can be gained. Table 4 shows that aggregating to a regional level is sufficient in principle, although not all strategies work equally well in all regions. The $\mathrm{E} / \mathrm{P}$ and $\mathrm{B} / \mathrm{M}$ value strategies earn significant excess returns in all regions, the 6-month momentum strategy outperforms the EWI in Europe/MiddleEast/Asia (EMEA) and Latin America but not in Asia, whereas the excess return of the ER FY1 revisions strategy is significant in Asia but not in EMEA and Latin America. The combined value, momentum and revisions strategy again generates outperformance against the EWI in all three regions.

\section{- insert Table 4 about here -}

\subsection{Stock Selection versus Country Selection}

The strategies considered in the above are "country-neutral". By selecting the top 15 percent ranked stocks by country, the resulting international portfolio takes no net position in any country. The excess returns of these strategies thus purely derive from stock selection. By contrast, most research on trading strategies in emerging markets has focused on country selection and, in fact, the same return factors that are found useful for individual stock selection here have been found useful for country selection, see Harvey (1995) and Bekaert et al. (1997), among others. ${ }^{6}$

We investigate whether country selection can add to the profitability of the stock selection strategies by ranking stocks globally and forming an equally weighted portfolio consisting of the top 15 percent stocks in this alternative ranking. This procedure implicitly allows the winners portfolio to take net positions in the different emerging market countries. The first two rows of Table 5 compare the excess returns of country-neutral strategies and global strategies. It is seen that including country selection doubles the excess returns of the E/P, B/M and E/R FY1 strategies and even quadruples the excess return of the 6-month momentum strategy. However, at the same time the volatility of the excess returns increases considerably, such that the $t$-statistics of the global strategies are of comparable magnitude or even smaller than for the country-neutral strategies.

\section{- insert Table 5 about here -}

\footnotetext{
${ }^{6}$ The same appears to be true for developed equity markets, see Asness, Liew and Stevens (1997) and Chan, Hameed and Tong (2000), among others.
} 
We decompose the excess returns of the global selection strategies into parts that are due to country selection and due to stock selection. ${ }^{7}$ The third and fourth rows of Table 5 show that for the E/P, B/M and ER FY1 strategies, country and stock selection contribute roughly equally to the total excess returns. The excess returns due to country selection are, however, much more volatile than the excess returns due to stock selection. Finally, it is noteworthy that the total excess return of the global 6-month momentum strategy is almost entirely due to country selection.

\section{Profitability in Practice}

The excess returns of the stock selection strategies presented in the previous section are based on the implicit assumption of perfect capital markets. A natural question to ask is whether these strategies are still profitable if applied in practice by a large investor. Market imperfections that may prevent successful implementation are lack of liquidity, restrictions on foreign ownership, the occurrence of outliers, and the presence of substantial transaction costs. We address this issue by evaluating the selection strategies under different circumstances, which account for each of these imperfections in turn. We concentrate on the univariate strategies based on $\mathrm{E} / \mathrm{P}$, B/M, 6-month momentum, earnings revisions for the current fiscal year and the multivariate value, momentum and revisions strategy. Tables 6 and 7 summarize the results of these tests which, in general, confirm the robustness of the strategies and the opportunities for using them in practice.

For a large investor, it is important that the stocks in the strategy portfolio have sufficient size and liquidity. Even though from the outset we have excluded the smallest stocks, with market capitalization below 100 million US dollars in December 1998, this might still be a cause for concern if the excess returns of the different strategies were mainly due to the smallest stocks in our universe. Therefore, we examine the performance of the strategies for different size segments. All stocks in the sample are divided according to market capitalization into three equally sized segments, which we call small, mid and large caps. In addition, we also report results for the stocks that were excluded at the outset of our analysis ("mini caps").

\footnotetext{
${ }^{7}$ If $w_{i}^{p}$ and $w_{i}^{b}$ denote the weights of country $i$ in the portfolio and the (equally weighted index) benchmark, respectively, and $r_{i}^{p}$ and $r_{i}^{b}$ denote the corresponding country returns, the total excess return of the global portfolio is given by $\sum_{i}\left(w_{i}^{p} r_{i}^{p}-w_{i}^{b} r_{i}^{b}\right)$. This can be written as $\sum_{i}\left(w_{i}^{p} r_{i}^{p}-w_{i}^{b} r_{i}^{b}\right)=$ $\sum_{i}\left(w_{i}^{p}-w_{i}^{b}\right) r_{i}^{p}+\sum_{i}\left(r_{i}^{p}-r_{i}^{b}\right) w_{i}^{b}$. The first term on the right-hand side then measures the contribution of country selection to the total excess return and the second term measures the contribution of stock selection.
} 
Table 6 shows that the $\mathrm{E} / \mathrm{P}$ and $\mathrm{B} / \mathrm{M}$ strategies generate the largest excess returns for the larger size segments, whereas the 6-month momentum strategy seems to work best for the excluded mini cap stocks. The earnings revisions strategy attains the best results for the small and mid cap size segments, but has a negative excess return for the excluded mini cap stocks. The latter result can be explained by the low analyst coverage for the smallest stocks. For the multivariate strategy, the excess returns are significant for all size segments although they are negatively related to size.

\section{- insert Table 6 about here -}

The excess returns from the different selection strategies thus are not limited to a certain size segment. Whether the excess returns actually can be realized in practice is, however, still not completely certain, because restrictions on foreign ownership may imply that not all stocks in the IFC emerging markets database are accessible to foreign investors, see Bekaert (1995). We therefore consider the performance of the selection strategies on a universe consisting only of stocks included in the IFC Investables index. As the name suggests, stocks which are included in this index are "investable", and can be bought and sold by foreign investors. The second row in Table 7 shows that the strategies retain their good results when selection is restricted to these stocks only.

\section{- insert Table 7 about here -}

Outliers are often considered to be a serious problem in emerging markets data. Several measures can be taken to guard against the possible influence of such anomalous observations. For example, Rouwenhorst (1999) excludes the extreme five percent of the past 6-month return distribution when forming momentum portfolios. Our results so far are based on the entire sample of stocks, without accounting for the presence of outliers at all. We examine to what extent our results are driven by return outliers by computing the excess returns of the different strategies when portfolio returns are measured by the median return of the stocks in the portfolio (instead of the mean return). This limits the influence of return outliers drastically. The third row in Table 7 shows that, except for the B/M strategy, all strategies perform well for median returns. Hence, we conclude that the profitability of the selection strategies is not due to return outliers.

Transaction costs in emerging equity markets can be substantial, see Bekaert et al. (1997), and may seriously erode profits from trade-intensive strategies such as 
the ones considered here. The fourth row in Table 7 shows excess returns from the selection strategies when transaction costs of 1 percent for each sale or purchase of stocks are taken into account. ${ }^{8}$ As expected, the profitability of the strategies worsens considerably, such that the excess return of the momentum strategy becomes negative and the excess return of the earnings revisions strategy is no longer significant. However, the excess returns of the $\mathrm{E} / \mathrm{P}$ and $\mathrm{B} / \mathrm{M}$ strategies and the multivariate strategy remain statistically significant. The fact that the returns of the momentum and revisions strategies suffer more from the introduction of transaction costs than the returns from the $\mathrm{E} / \mathrm{P}, \mathrm{B} / \mathrm{M}$ and multivariate strategies is caused by the fact that the former strategies are more trade intensive and have a higher turnover ratio.

The portfolios we have constructed so far are equally weighted. In practice, an investor might want to apply some sort of value-weighting scheme and, furthermore, results of stock selection strategies for value-weighted and equally weighted portfolios are sometimes found to differ substantially, see Achour et al. (1998), for example. In our final test we therefore use a portfolio consisting of all stocks weighted according to their market capitalization as benchmark. To construct the winners portfolio, we start with this value-weighted benchmark and underweight stocks outside the top 15 percent rankings with a maximum of 1 percent, without allowing short positions. The stocks with the top 15 percent rankings are subsequently equally overweighted. This way of constructing a weighted portfolio mimicks the practice among portfolio managers more closely than, for example, constructing a weighted portfolio only from the top 15 percent rankings according to their market capitalization. The results based on these value-weighted portfolios, shown in the final row of Table 7 , are very similar to the results involving equally weighted portfolios.

\section{Explanations for the Profitability of Selection Strategies}

There is an ongoing debate concerning the sources and interpretation of the profits from value, momentum and revisions strategies that are consistently found in both developed and emerging markets. Roughly speaking, the competing explanations

\footnotetext{
${ }^{8}$ The estimates of actual transaction costs in Bekaert et al. (1997) show that transaction costs vary substantially among emerging markets. The assumption of identical transaction costs in all countries thus obviously is an abstraction from reality. Note however that the assumed transaction costs of 1 percent is quite close to the mean of the estimates reported in Bekaert et al. (1997).
} 
can be grouped under the headings "compensation for risk" on the one hand and "market inefficiency" on the other. In this section, we first examine whether the selection strategies that we consider have a higher market risk or lower liquidity than the market average. We find no substantial evidence that this is the case. Next, we examine whether the results are consistent with behavioral explanations involving irrational behavior of investors.

\subsection{Risk and Liquidity}

To evaluate the risk of the trading strategies, we compare the annualized volatility of the returns of the winners portfolio and the equally weighted index of all stocks, and estimate alphas and betas based on the same set of returns. Table 8 shows that for all strategies the volatility of the winners portfolio returns is only moderately higher than the volatility of the average return of the universe of stocks, whereas the volatility on the earnings revisions portfolio is even slightly lower. Furthermore, the right panel of Table 8 shows that the betas of the winners portfolios are close to one. The excess returns from the E/P, B/M, ER FY1 and VMR strategies after correcting for market risk, as measured by the intercept $\alpha$, remain statistically significant. These results do not rule out the possibility of additional risk factors as explanation of the profitability of the trading strategies, as in Fama and French (1996, 1998) and Davis, Fama and French (2000), among others. However, the results do show that the excess returns are not just a reward for additional market risk. For example, for the multivariate VMR strategy, an additional volatility of less than 1 percent or a beta of 1.01 cannot reasonably justify the annual excess return of about 7 percent.

\section{- insert Table 8 about here -}

To examine the liquidity of the strategies, we consider the median market capitalization and the median turnover ratio for both the winners portfolio and the equally weighted index of all stocks. Recall that the turnover ratio is defined as the number of shares traded each month divided by the number of outstanding shares. Table 9 shows that the $\mathrm{B} / \mathrm{M}$ and, to a lesser extent, the $\mathrm{E} / \mathrm{P}$ strategies tend to select smaller stocks, whereas the 6MR, ER FY1 and VMR strategies select larger stocks on average. The turnover ratio for all winners portfolios is equal to or higher than the turnover ratio for the complete sample of stocks. Concluding, liquidity may be lower for value stocks, but it is higher for stocks selected by the momentum, earnings 
revisions and multivariate strategies. Therefore, liquidity can not explain the excess returns completely. Additional evidence that the trading profits are not merely compensations for size or liquidity is provided by Table 1, where it was already seen that smaller and less liquid stocks actually generate a slightly lower return on average than larger and more liquid stocks.

\section{- insert Table 9 about here -}

\subsection{A Behavioral Explanation for Value Strategies}

Lakonishok, Shleifer and Vishny (1994) provide a behavioral explanation for the superior returns of value strategies. They argue that investors overestimate the actual difference in future earnings growth between glamour and value stocks. Investors are overly optimistic about glamour stocks and excessively pessimistic about value stocks because they simply extrapolate past growth rates into the future, failing to impose mean reversion on their growth forecasts. Their higher $\mathrm{E} / \mathrm{P}$ ratios imply that value stocks are expected to continue to show lower earnings growth in the future. In practice, they indeed do experience lower earnings growth, but to a lesser extent and for a much shorter period than the market implicitly expects. Using a sample of US stocks, Lakonishok et al. (1994) demonstrate that by various measures of growth, including earnings, glamour stocks grew much faster than value stocks before portfolio formation. Over a 5-year post-portfolio formation period, earnings growth rates were found to be lower for value stocks than for glamour stocks for the first two years, but this was reversed over the following 3 years, resulting in approximately equal growth rates over the complete 5-year period. The economic rationale behind these findings is that competition among companies makes above average earnings growth only sustainable for short periods of time. According to this behavioral explanation, "naive" investors do not fully take this "economic law" into account when forecasting earnings growth, but extrapolate past growth rates too far into the future. Value strategies generate superior returns because they are "contrarian" to these naive extrapolation strategies.

To examine whether this behavioral explanation may account for the excess returns of the value strategies in emerging markets, we examine how earnings of the $\mathrm{E} / \mathrm{P}$ winners portfolio and of the corresponding universe of stocks develop after portfolio formation. Figure 2 shows the average earnings as a percentage of the initial invested capital for the first 3 years after portfolio formation. At formation, this equals the earnings yield, which is naturally higher for the $\mathrm{E} / \mathrm{P}$ portfolio. Over the 
next 12 to 18 months, average earnings of the value portfolio fall, whereas earnings of the average stock in the sample rise. However, the earnings level of the value portfolio remains above the earnings level of the universe. More importantly, after 18 months, approximately, earnings growth rates are about equal, such that the difference in earnings levels remains fairly constant subsequently. ${ }^{9}$ This may lead to valuation ratios for the value portfolio that are more in line with the market average.

\section{- insert Figure 2 about here -}

Figure 3 shows the average $\mathrm{P} / \mathrm{E}$-ratios of the $\mathrm{E} / \mathrm{P}$ portfolio and the universe of stocks for each month after portfolio formation, confirming the relative increase in the $\mathrm{P} / \mathrm{E}$-ratio of the value portfolio. On average the $\mathrm{P} / \mathrm{E}$-ratio of the value stocks increases by 127 percent over the first three years after portfolio formation, which more than compensates the average decline in earnings of 26 percent. By contrast, the average $\mathrm{P} /$ E-ratio of all stocks in the universe increases by only 20 percent over the same period.

\section{- insert Figure 3 about here -}

Concluding, the differences in valuation ratios between value and growth stocks are not justified by later earnings developments. After a year and a half, the earnings growth rate of value stocks is equal to the growth rate of the average stock. Hence, we conclude that our positive results for value strategies in emerging markets are consistent with the behavioral explanation of Lakonishok et al. (1994). ${ }^{10}$ It should be noted, however, that one may still argue that the excess returns of value strategies are due to an additional risk factor. Our results do not reject this explanation.

\subsection{A Behavioral Explanation for Momentum and Earnings Revisions Strategies}

Chan, Jegadeesh and Lakonishok (1996) put forward a behavioral explanation for the profitability of momentum and earnings revisions strategies, based on the idea that financial markets respond only gradually to new information, to earnings-related

\footnotetext{
${ }^{9}$ Extending the post-formation period to five years, we find that for the fourth and fifth year after portfolio formation, value stocks even have higher earnings growth than the average stock in the sample.

${ }^{10}$ Laporta et al. (1997) further examine this behavioral explanation for US stocks by studying stock price reactions around earnings announcement dates during the post-formation period. Unfortunately, comparable data are not available for the emerging markets.
} 
news in particular. Using a sample of US stocks, they find empirical evidence that stocks with high price momentum or high past earnings revisions have higher returns around earnings announcements, higher earnings revisions and higher earnings surprises for some time after portfolio formation. Momentum and earnings revisions strategies thus are successful because they exploit the initial under-reaction of the market to the information in past returns and past earnings revisions.

Figure 4 shows how earnings revisions for the winners portfolio from the ER FY1 strategy and the universe of emerging market stocks develop during the three years after portfolio formation. Recall that our measure of earnings revisions is defined as the number of analysts with upward revisions minus the number of analysts with downward revisions, divided by the total number of analysts providing an earnings forecast in a particular month. Notice that for the average stock in the sample, there are more downward than upward revisions for each month in the post-formation period. This demonstrates the notion that analysts initially tend be overly optimistic and adjust their earnings forecasts downward only gradually. ${ }^{11}$ The earnings revisions of the winners portfolio remain higher than the earnings revisions for the complete sample until 10 months after portfolio formation. This is consistent with the behavioral explanation of Chan et al. (1996) that the market does not incorporate news in past earnings revisions promptly.

\section{- insert Figure 4 about here -}

\subsection{Comparing Behavioral Explanations}

Finally, we compare the behavioral explanations for the value strategies and for the momentum and revisions strategies discussed above. In particular, we inspect the earnings revisions for the value strategies during the post-formation period, and the earnings growth for the momentum and revisions strategies. We use the same computation method as for calculating excess returns, that is, we compute averages for the six winners portfolios that are held each month and for the corresponding universes of stocks. The table reports the difference between these monthly averages

\footnotetext{
${ }^{11}$ In addition to systematic positive bias in analysts' earnings forecasts (see Easterwood and Nutt (1999) for recent evidence), the extent of this bias has also been found to be predictable from observable firm characteristics, see Abarbanell and Bernard (1992), among others. Analysts' forecasts are therefore usually dismissed as being irrational or inaccurate. Recently, Lim (2001) showed that positively and predictably biased forecasts may in fact be optimal if the incentive structure of analysts is taken into account. If analysts balance forecast accuracy and improved access to management information, such biased forecasts are rational.
} 
for the winners portfolio and the universe, averaged over the first 36 months after portfolio formation.

Table 10 shows that earnings growth and the $\mathrm{P} / \mathrm{E}$ ratio for the $\mathrm{B} / \mathrm{M}$ value strategy develop in much the same way as for the E/P strategy. Earnings decline by more than 3 percent per month on average, which is, however, more than compensated for by the rise in $\mathrm{P} / \mathrm{E}$-ratio of almost 4 percent per month. Furthermore, both value strategies have more downward than upward earnings revisions on average, indicating that earnings drop even more than expected at portfolio formation. Apparently, the outperformance of the value strategies is not due to better than expected earnings, but due to better than expected long term growth rates, as the improvement in $\mathrm{P} /$ E-ratio suggests.

Earnings revisions for the $6 \mathrm{MR}$ momentum strategy are similar to those for the ER FY1 strategy. For both strategies, analysts revise their earnings forecasts upwards more often than downwards. Therefore, the results for the momentum strategy are consistent with the behavioral explanation for the earnings revisions strategy discussed in the previous section. ${ }^{12}$ Furthermore, we find that the $\mathrm{P} / \mathrm{E}$ ratio for both strategies decreases on average, which is more than compensated for by the growth in earnings. This effect seems rather weak for the revisions strategy, but this is mostly due to instability in the results until 1992. From 1993 onward, the results of the momentum and revisions strategies are more alike.

The multivariate strategy has the best of both worlds. After portfolio formation, earnings growth is lower than for the complete market, which is more than compensated for by a higher growth rate of the P/E-ratio. Still, earnings grow faster than expected, as indicated by the positive value of earnings revisions.

\section{Conclusions}

In this paper we have confirmed the profitability of trading strategies based on value and momentum in emerging markets. In addition, a selection strategy based on

\footnotetext{
${ }^{12}$ Jegadeesh and Titman (2001) examine different explanations for the profitability of momentum strategies by considering the post-holding period excess returns. According to Conrad and Kaul (1998), momentum profits are simply an artefact due to differences in unconditional expected returns across stocks. This implies that profits from momentum strategies should persist after the initial holding period. By contrast, behavioral models, such as the ones in Barberis, Shleifer and Vishny (1998), Daniel, Hirshleifer and Subrahmanyam (1998) and Hong and Stein (1999), imply that excess returns of momentum portfolios should become zero or negative after the initial holding period. These theoretical models do not offer any guidance, however, regarding the length of the post-holding period over which these return reversals should occur.
} 
past analysts' earnings revisions was also found to outperform an equally weighted index of all stocks. The performances of the separate strategies can be enhanced by combining value, momentum and revisions into a multivariate strategy. The strategies can best be applied simultaneously in all emerging markets, as the results are rather unstable for individual countries. Using the strategies for country selection as well increases profitability considerably, but at the cost of higher risk.

Our results show that the trading strategies can be implemented successfully in practice by a large investor. The profits of most strategies remain significant for large caps, after correcting for outliers, and after transaction costs.

We do not find evidence that the strategies have higher market risk or have a tendency to trade stocks with lower liquidity. Instead, the results are consistent with behavioral explanations. For value stocks, there appears to be an overreaction, as their lower valuation is not justified by later earnings developments. For stocks with high momentum or earnings revisions by analysts, there seems to be an initial underreaction to earnings news, as these stocks continue to have high upward earnings revisions for more than six months after portfolio formation.

\section{References}

Abarbanell, Jeffrey S., and Victor L. Bernard, 1992, Tests of analysts' overreaction/underreaction to earnings information as an explanation for anomalous stock-price behavior, Journal of Finance 47, 1181-1207.

Achour, Dana, Campbell R. Harvey, Greg Hopkins, and Clive Lang, 1998, Stock selection in emerging markets: portfolio strategies for Malaysia, Mexico and South Africa, Emerging Markets Quarterly 2, 38-91.

Alexander, Gordon J., 2000, On back-testing "zero-investment" strategies, Journal of Business 73, 255-278.

Arshanapalli, Bala, T. Daniel Coggin, and John Doukas, 1998, Multifactor asset pricing analysis of international value investment strategies, Journal of Portfolio Management 24, 10-23.

Asness, Clifford S., John M. Liew, and Ross L. Stevens, 1997, Parallels between the crosssectional predictability of stock and country returns - striking similarities in the predictive power of value, momentum and size, Journal of Portfolio Management 23, 79-87.

Barberis, Nicholas, Andrei Shleifer, and Robert W. Vishny, 1998, A model of investor sentiment, Journal of Financial Economics 49, 307-343.

Bauman, W. Scott, C. Mitchell Conover and Robert E. Miller, 1998, Growth stocks versus value stocks and large versus small cap stocks in international markets, Financial Analysts Journal 54, 75-89.

Bauman, W. Scott, C. Mitchell Conover and Robert E. Miller, 1999, Investor overreaction 
in international stock markets - value stocks outperform outside the US, Journal of Portfolio Management 25, 102-111.

Baytas, Ahmet and Nusret Cakici, 1999, Do markets overreact: international evidence, Journal of Banking and Finance 23, 1121-1144.

Bekaert, Geert, 1995, Market integration and investment barriers in emerging equity markets, World Bank Economic Review 9, 75-107.

Bekaert, Geert, and Campbell R. Harvey, 2000a, Capital flows and the behavior of emerging market equity returns, in Sebastian Edwards (ed.), Capital Flows and the Emerging Economies: Theory, Evidence and Controversies, Chicago: University of Chicago Press, pp. 159-194.

Bekaert, Geert, and Campbell R. Harvey, 2000b, Foreign speculators and emerging equity markets, Journal of Finance 55, 565-614.

Bekaert, Geert, and Michael S. Urias, 1996, Diversification, integration, and emerging market closed-end funds, Journal of Finance 51, 835-870.

Bekaert, Geert, and Michael S. Urias, 1999, Is there a free lunch in emerging market equities? In some markets, but investors need to be more selective going forward, Journal of Portfolio Management 25, 83-95.

Bekaert, Geert, Claude B. Erb, Campbell R. Harvey, and Tadas E. Viskanta, 1997, What matters for emerging equity market investments, Emerging Markets Quarterly 1, $17-46$.

Bekaert, Geert, Claude B. Erb, Campbell R. Harvey, and Tadas E. Viskanta, 1998, Distributional characteristics of emerging market returns and asset allocation, Journal of Portfolio Management 24, 102-116.

Bercel, Anthony, 1994, Consensus expectations and international equity returns, Financial Analysts Journal 50, 76-80.

Capaul, Carlo, Jan Rowley, and William F. Sharpe, 1993, International value and growth stock returns, Financial Analyst Journal 49, 27-41.

Chan, Louis K.C., Narashimhan Jegadeesh, and Josef Lakonishok, 1996, Momentum strategies, Journal of Finance 51, 1681-1713.

Chan, Kalok, Allaudeen Hameed, and Wilson Tong, 2000, Profitability of momentum strategies in the international equity markets, Journal of Financial and Quantitative Analysis 35, 153-172.

Claessens, Stijn, Susmita Dasgupta, and Jack Glen, 1998, The cross section of stock returns: Evidence from emerging markets, Emerging Markets Quarterly 2, 4-13.

Conrad, Jennifer and Gautam Kaul, 1998, An anatomy of trading strategies, Review of Financial Studies 11, 489-519.

Daniel, Kent, David Hirshleifer, and Avanidhar Subrahmanyam, 1998, Investor psychology and security market under- and overreactions, Journal of Finance 53, 1839-1885.

Davis, James L., Eugene F. Fama, and Kenneth R. French, 2000, Characteristics, covariances and average returns, Journal of Finance 55, 389-406.

De Bondt, Werner F.M., and Richard H. Thaler, 1985, Does the stock market overreact?, Journal of Finance 40, 793-805.

De Bondt, Werner F.M., and Richard H. Thaler, 1987, Further evidence on investor over- 
reaction and stock market seasonality, Journal of Finance 42, 557-581.

De Roon, Frans A., Theo E. Nijman, and Bas J.M. Werker, 2001, Testing for mean-variance spanning with short sales constraints and transaction costs: the case of emerging markets, Journal of Finance, to appear.

Easterwood, John C., and Stacey R. Nutt, 1999, Inefficiency in analysts' earnings forecasts: systematic misreaction or systematic optimism?, Journal of Finance 54, 1777-1797.

Fama, Eugene F. and Kenneth R. French, 1996, Multifactor explanations of asset pricing anomalies, Journal of Finance 51, 55-84.

Fama, Eugene F. and Kenneth R. French, 1998, Value versus growth: the international evidence, Journal of Finance 53, 1975-1999.

Harvey, Campbell R., 1995, Predictable risk and return in emerging markets, Review of Financial Studies 8, 773-816.

Henry, Peter B., 2000, Stock market liberalization, economic reform, and emerging market equity prices, Journal of Finance 55, 529-564.

Haugen, Robert A. and Nardin L. Baker, 1996, Commonality in the determinants of expected stock returns, Journal of Financial Economics 41, 401-439.

Hong, Harrison, and Jeremy C. Stein, 1999, A unified theory of underreaction, momentum trading, and overreaction in asset markets, Journal of Finance 54, 2143-2184.

Jegadeesh, Narashimhan, 1990, Evidence of predictable behavior of security returns, Journal of Finance 45, 881-898.

Jegadeesh, Narashimhan and Sheridan Titman, 1993, Returns to buying winners and selling losers: implications for stock market efficiency, Journal of Finance 48, 6591.

Jegadeesh, Narashimhan and Sheridan Titman, 2001, Profitability of momentum strategies: an evaluation of alternative explanations, Journal of Finance, to appear.

Lakonishok, Josef, Andrei Shleifer, and Robert W. Vishny, 1994, Contrarian investment, extrapolation and risk, Journal of Finance 49, 1541-1578.

LaPorta, Rafael, Josef Lakonishok, Andrei Shleifer, and Robert W. Vishny, 1997, Good news for value stocks: further evidence on market efficiency, Journal of Finance 52, 859-874.

Lehmann, Bruce N., 1990, Fads, martingales and market efficiency, Quarterly Journal of Economics 60, 1-28.

Lim, Terence, 2001, Rationality and analysts' forecast bias, Journal of Finance, to appear.

Patel, Sandeep A., 1998, Cross-sectional variation in emerging markets equity returns, January 1988-March 1997, Emerging Markets Quarterly 2, 57-70.

Rouwenhorst, K. Geert, 1998, International momentum strategies, Journal of Finance 53, $267-284$.

Rouwenhorst, K. Geert, 1999, Local return factors and turnover in emerging stock markets, Journal of Finance 54, 1439-1464. 
Table 1: Returns of Univariate Stock Selection Strategies

\begin{tabular}{lccrcrrrr}
\hline \hline Factor & \# Stocks & Top & EWI & Bottom & TMI & $t$ (TMI) & TMB & $t$ (TMB) \\
\hline E/P & 685 & 1.89 & 1.35 & 0.88 & 0.53 & 4.45 & 1.02 & 5.46 \\
B/M & 684 & 1.83 & 1.33 & 1.00 & 0.49 & 2.99 & 0.83 & 3.18 \\
D/P & 625 & 1.76 & 1.67 & 1.34 & 0.09 & 0.81 & 0.42 & 2.52 \\
E/P FY1 & 593 & 0.87 & 0.69 & 0.63 & 0.18 & 1.42 & 0.25 & 1.06 \\
E/P FY2 & 579 & 0.72 & 0.58 & 0.49 & 0.14 & 0.90 & 0.24 & 0.91 \\
1MR & 696 & 1.41 & 1.52 & 1.45 & -0.11 & -1.32 & 0.00 & 0.01 \\
3MR & 694 & 1.63 & 1.54 & 1.29 & 0.09 & 0.96 & 0.37 & 2.26 \\
6MR & 692 & 1.69 & 1.55 & 1.24 & 0.14 & 1.41 & 0.48 & 2.63 \\
9MR & 689 & 1.77 & 1.59 & 1.27 & 0.18 & 1.68 & 0.52 & 2.67 \\
12MR & 685 & 1.81 & 1.62 & 1.45 & 0.19 & 1.55 & 0.38 & 1.84 \\
36MR & 625 & 1.72 & 1.64 & 1.52 & 0.08 & 0.49 & 0.20 & 0.93 \\
ER FY1 & 584 & 0.76 & 0.45 & 0.22 & 0.31 & 3.43 & 0.56 & 4.22 \\
ER FY2 & 543 & 0.94 & 0.62 & 0.31 & 0.32 & 3.28 & 0.65 & 4.51 \\
size & 697 & 1.41 & 1.52 & 1.60 & -0.11 & -0.85 & -0.19 & -0.88 \\
liquidity & 684 & 1.06 & 1.25 & 1.24 & -0.18 & -1.04 & -0.19 & -0.75 \\
\hline
\end{tabular}

At the beginning of each month all stocks for which the necessary information is available are ranked by country in descending order according to the value of the factor indicated in the first column. The rankings according to $1 \mathrm{MR}, 36 \mathrm{MR}$, size and liquidity are in ascending order. Equally weighted portfolios are formed from the top and bottom 15 percent of stocks, which are combined into equally weighted internationally diversified portfolios (Top and Bottom). EWI is the equally weighted portfolio of all stocks in the sample. Column 2 reports the average number of stocks in the different samples. Positions are held for six months and are not rebalanced. Columns 3-5 report the average returns of the Top, EWI and Bottom portfolios, expressed as percentage per month. Columns 6-7 and 8-9 report the average excess returns and the corresponding $t$-statistics of the Top Minus EWI (TMI) portfolio and the Top Minus Bottom (TMB) portfolio, respectively. 
Table 2: Returns of Multivariate Stock Selection Strategies

\begin{tabular}{lccccccc}
\hline \hline Strategy & Top & EWI & Bottom & TMI & $t$ (TMI) & TMB & $t$ (TMB) \\
\hline Value & 1.99 & 1.37 & 0.77 & 0.60 & 4.45 & 1.22 & 4.97 \\
Momentum & 1.72 & 1.55 & 1.29 & 0.17 & 1.60 & 0.44 & 2.23 \\
Revisions & 0.78 & 0.48 & 0.19 & 0.30 & 3.14 & 0.61 & 4.40 \\
VM & 2.02 & 1.50 & 0.92 & 0.51 & 5.04 & 1.11 & 5.87 \\
VR & 1.97 & 1.35 & 0.67 & 0.62 & 4.76 & 1.31 & 5.86 \\
MR & 1.81 & 1.55 & 1.28 & 0.26 & 2.64 & 0.54 & 3.02 \\
VMR & 2.07 & 1.50 & 0.88 & 0.56 & 5.79 & 1.19 & 6.85 \\
\hline
\end{tabular}

At the beginning of each moment, normalized values of $\mathrm{E} / \mathrm{P}$ and $\mathrm{B} / \mathrm{M}$ (value), past 6 - and 12 month returns (momentum), and earnings revisions for the current and next fiscal year (revisions) are computed by subtracting the median and dividing by the cross-sectional median absolute deviation, and trimming the normalized values at plus and minus 3 . The score for the multivariate strategies is obtained as the sum of the normalized values of the relevant variables. All stocks for which the relevant score is available are ranked by country in descending order. Equally weighted portfolios are formed from the top and bottom 15 percent of stocks, which are combined into equally weighted internationally diversified portfolios (Top and Bottom). EWI is the equally weighted portfolio of all stocks in the sample. Positions are held for six months and are not rebalanced. Columns 2-4 report the average returns of the Top, EWI and Bottom portfolios, expressed as percentage per month. Columns 5-6 and 7-8 report the average excess returns and the corresponding $t$-statistics of the Top Minus EWI (TMI) portfolio and the Top Minus Bottom (TMB) portfolio, respectively. VM denotes the value and momentum strategy, VR value and revisions, MR momentum and revisions, and VMR value, momentum and revisions. 


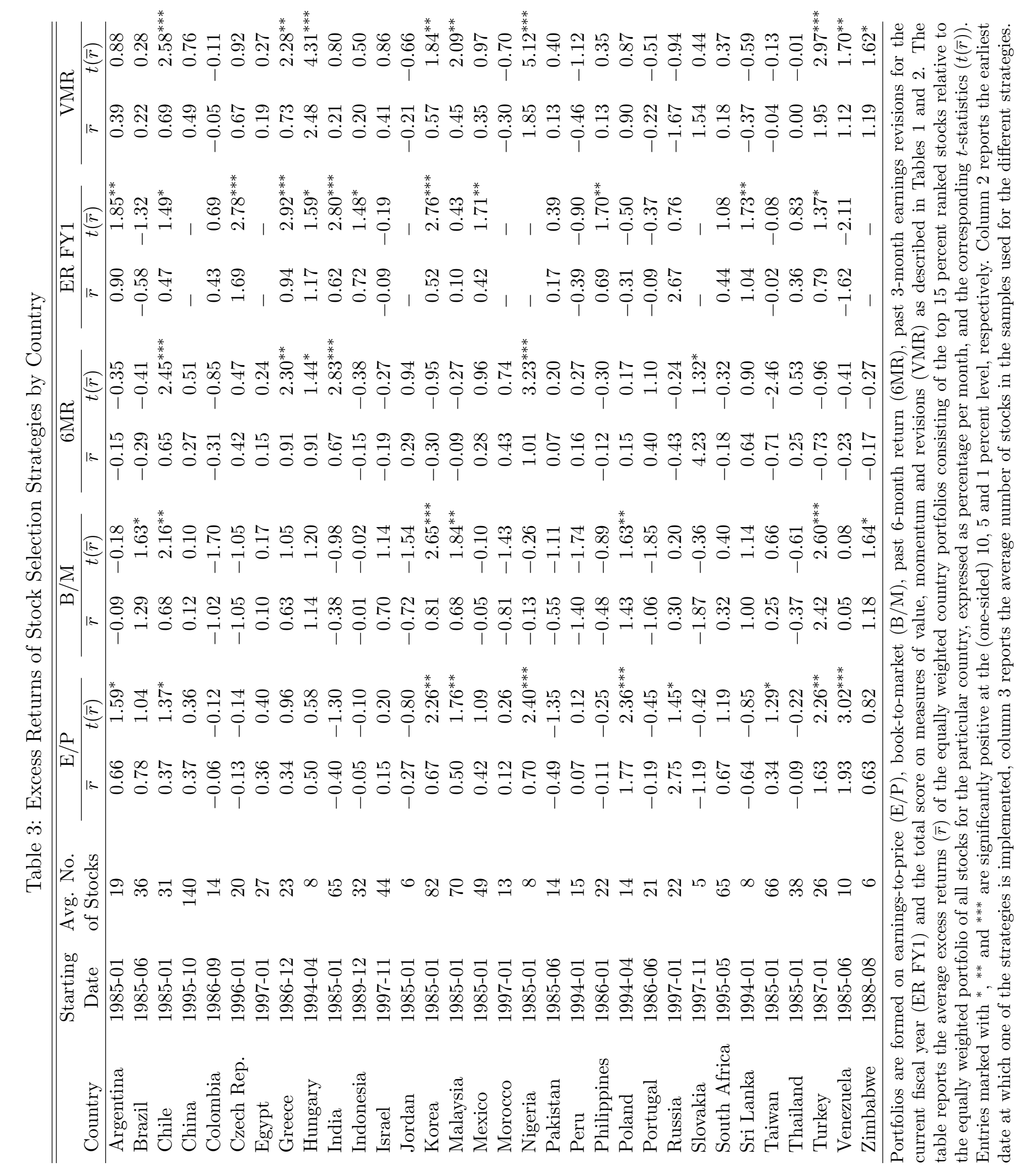


Table 4: Excess Returns of Stock Selection Strategies by Region

\begin{tabular}{|c|c|c|c|c|c|c|c|c|c|c|}
\hline \multirow[b]{2}{*}{ Region } & \multicolumn{2}{|c|}{$\mathrm{E} / \mathrm{P}$} & \multicolumn{2}{|c|}{$\mathrm{B} / \mathrm{M}$} & \multicolumn{2}{|c|}{$6 \mathrm{MR}$} & \multicolumn{2}{|c|}{ "ER FY1 } & \multicolumn{2}{|c|}{ VMR } \\
\hline & $\bar{r}$ & $t(\bar{r})$ & $\bar{r}$ & $t(\bar{r})$ & $\bar{r}$ & $t(\bar{r})$ & $\bar{r}$ & $t(\bar{r})$ & $\bar{r}$ & $t(\bar{r})$ \\
\hline Asia & 0.38 & 1.99 & 0.32 & 2.08 & 0.065 & 0.48 & 0.35 & 2.38 & 0.40 & 3.29 \\
\hline EMEA & 1.08 & 3.64 & 0.59 & 2.13 & 0.44 & 1.68 & 0.23 & 0.83 & 0.99 & 3.77 \\
\hline Latin America & 0.77 & 2.79 & 0.65 & 2.72 & 0.32 & 1.57 & 0.41 & 1.02 & 0.64 & 2.86 \\
\hline
\end{tabular}

Portfolios are formed on earnings-to-price (E/P), book-to-market (B/M), past 6-month return (6MR), past 3-month earnings revisions for the current fiscal year (ER FY1) and the total score on measures of value, momentum and revisions (VMR) as described in Tables 1 and 2. The table reports the average excess returns $(\bar{r})$ of the equally weighted regional portfolios consisting of the top 15 percent ranked stocks relative to the equally weighted portfolio of all stocks for the particular region, expressed as percentage per month, and the corresponding $t$-statistics $(t(\bar{r}))$. Asia includes China, India, Indonesia, Korea, Malysia, Pakistan, Philippines, Sri Lanka, Taiwan and Thailand; EMEA includes Czech Republic, Egypt, Greece, Hungary, Israel, Jordan, Morocco, Nigeria, Poland, Portugal, Russia, Slovakia, South Africa, Turkey and Zimbabwe; Latin America includes Argentina, Brazil, Chile, Colombia, Mexico, Peru and Venezuela.

Table 5: Excess Returns of Country-Neutral and Global Stock Selection Strategies

\begin{tabular}{|c|c|c|c|c|c|c|c|c|c|c|}
\hline \multirow[b]{2}{*}{ Region } & \multicolumn{2}{|c|}{$\mathrm{E} / \mathrm{P}$} & \multicolumn{2}{|c|}{$\mathrm{B} / \mathrm{M}$} & \multicolumn{2}{|c|}{$\overline{6 \mathrm{GMR}}$} & \multicolumn{2}{|c|}{ ER FY1 } & \multicolumn{2}{|c|}{ VMR } \\
\hline & $\bar{r}$ & $t(\bar{r})$ & $\bar{r}$ & $t(\bar{r})$ & $\bar{r}$ & $t(\bar{r})$ & $\bar{r}$ & $t(\bar{r})$ & $\bar{r}$ & $t(\bar{r})$ \\
\hline Country-neutral & 0.53 & 4.45 & 0.49 & 2.99 & 0.14 & 1.41 & 0.31 & 3.43 & 0.56 & 5.79 \\
\hline Global & 1.12 & 3.52 & 0.96 & 3.37 & 0.61 & 1.67 & 0.58 & 2.36 & 1.45 & 4.67 \\
\hline Country selection & 0.49 & 1.88 & 0.46 & 1.79 & 0.57 & 1.74 & 0.31 & 1.33 & 0.95 & 3.61 \\
\hline Stock selection & 0.63 & 5.16 & 0.50 & 5.12 & 0.042 & 0.36 & 0.27 & 2.87 & 0.50 & 4.69 \\
\hline
\end{tabular}

Portfolios for the country-neutral strategies are formed on earnings-to-price (E/P), book-to-market $(\mathrm{B} / \mathrm{M})$, past 6-month return $(6 \mathrm{MR})$, past 3-month earnings revisions for the current fiscal year (ER FY1) and the total score on measures of value, momentum and revisions (VMR) as described in Tables 1 and 2. Portfolios for the global strategies are formed ranking stocks globally. The first two rows of the table report the average excess returns $(\bar{r})$ of the equally weighted portfolios consisting of the top 15 percent ranked stocks relative to the equally weighted portfolio of all stocks in the sample, expressed as percentage per month, and the corresponding $t$-statistics $(t(\bar{r}))$. The final two rows show the decomposition of the total excess return of the global strategies into parts due to country selection and stock selection. 
Table 6: Excess Returns of Stock Selection Strategies by Size Segment

\begin{tabular}{|c|c|c|c|c|c|c|c|c|c|c|}
\hline \multirow{2}{*}{$\begin{array}{l}\text { Size } \\
\text { Segment }\end{array}$} & \multicolumn{2}{|c|}{$\overline{\mathrm{E} / \mathrm{P}}$} & \multicolumn{2}{|c|}{$\overline{\mathrm{B} / \mathrm{M}}$} & \multicolumn{2}{|c|}{ 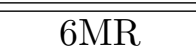 } & \multicolumn{2}{|c|}{ ER FY1 } & \multicolumn{2}{|c|}{$\overline{\overline{\text { VMR }}}$} \\
\hline & $\bar{r}$ & $t(\bar{r})$ & $\bar{r}$ & $t(\bar{r})$ & $\bar{r}$ & $t(\bar{r})$ & $\bar{r}$ & $t(\bar{r})$ & $\bar{r}$ & $t(\bar{r})$ \\
\hline Mini Caps & 0.33 & 1.54 & 0.61 & 2.38 & 0.48 & 2.43 & -0.17 & -0.53 & 0.43 & 2.39 \\
\hline Small Caps & 0.26 & 1.22 & 0.13 & 0.57 & 0.33 & 1.53 & 0.78 & 2.42 & 0.64 & 3.35 \\
\hline Mid Caps & 0.84 & 4.30 & 0.74 & 2.76 & 0.03 & 0.13 & 0.69 & 2.20 & 0.50 & 2.26 \\
\hline Large Caps & 0.48 & 2.64 & 0.60 & 2.04 & 0.07 & 0.34 & 0.20 & 1.81 & 0.43 & 2.60 \\
\hline
\end{tabular}

All stocks in the sample are divided according to market capitalization into three equally sized segments, denoted as Small, Mid and Large caps. Mini caps are stocks with market capitalization smaller than 100 million US dollars in December 1998 (deflated at 10 percent annually). Portfolios are formed on earningsto-price $(\mathrm{E} / \mathrm{P})$, book-to-market $(\mathrm{B} / \mathrm{M})$, past 6-month return $(6 \mathrm{MR})$, past 3-month earnings revisions for the current fiscal year (ER FY1) and the total score on measures of value, momentum and revisions (VMR) as described in Tables 1 and 2 for each size segment separately. The table reports the average excess returns $(\bar{r})$ of the equally weighted portfolios consisting of the top 15 percent ranked stocks relative to the equally weighted portfolio of all stocks for the size segment, expressed as percentage per month, and the corresponding $t$-statistics $(t(\bar{r}))$.

Table 7: Excess Returns of Modified Stock Selection Strategies

\begin{tabular}{|c|c|c|c|c|c|c|c|c|c|c|}
\hline \multirow[b]{2}{*}{ Test } & \multicolumn{2}{|c|}{$\mathrm{E} / \mathrm{P}$} & \multicolumn{2}{|c|}{$\mathrm{B} / \mathrm{M}$} & \multicolumn{2}{|c|}{$6 \mathrm{MR}$} & \multicolumn{2}{|c|}{ ER FY1 } & \multicolumn{2}{|c|}{ VMR } \\
\hline & $\bar{r}$ & $t(\bar{r})$ & $\bar{r}$ & $t(\bar{r})$ & $\bar{r}$ & $t(\bar{r})$ & $\bar{r}$ & $t(\bar{r})$ & $\bar{r}$ & $t(\bar{r})$ \\
\hline Perfect Markets & 0.53 & 4.45 & 0.49 & 2.99 & 0.14 & 1.41 & 0.31 & 3.43 & 0.56 & 5.79 \\
\hline IFC Investables & 0.37 & 2.54 & 0.62 & 3.58 & 0.23 & 1.54 & 0.26 & 2.09 & 0.54 & 4.97 \\
\hline Median Returns & 0.30 & 2.97 & -0.06 & -0.47 & 0.28 & 3.24 & 0.38 & 4.70 & 0.47 & 5.71 \\
\hline Transaction Costs & 0.35 & 2.93 & 0.34 & 2.08 & -0.13 & -1.31 & 0.05 & 0.59 & 0.35 & 3.55 \\
\hline Value Weighted & 0.67 & 4.48 & 0.65 & 3.70 & 0.33 & 2.81 & 0.48 & 3.07 & 0.66 & 5.27 \\
\hline
\end{tabular}

Portfolios are formed on earnings-to-price (E/P), book-to-market (B/M), past 6-month return (6MR), past 3-month earnings revisions for the current fiscal year (ER FY1) and the total score on measures of value, momentum and revisions (VMR) as described in Tables 1 and 2. The row labelled "Perfect Markets" repeats the results from Table 1 and 2 for equally weigthed portfolios without market imperfections. For the row labelled "IFC Investables", the sample is limited to stocks which are included in the IFC Investables index. For the row labelled "Median Returns", portfolio returns are measured as the median return of the stocks in the portfolio. The row labelled "Transaction Costs" contains results when transaction costs of 1 percent for each sale or purchase of stocks are assumed. The row "Value weighted" is based on value-weighted portfolios, as described in the text. The table reports the average excess returns $(\bar{r})$ of the portfolios consisting of the top 15 percent ranked stocks relative to the benchmark portfolio of all stocks in the sample, expressed as percentage per month, and the corresponding $t$-statistics $(t(\bar{r}))$. 
Table 8: Risk of Stock Selection Strategies

\begin{tabular}{lccccccc}
\hline \hline & \multicolumn{3}{c}{ Volatility } & & \multicolumn{4}{c}{ Regression } \\
\cline { 2 - 3 } \cline { 6 - 8 } Strategy & Top & EWI & & $\alpha$ & $t(\alpha)$ & $\beta$ & $t(\beta-1)$ \\
\hline E/P & 21.0 & 20.3 & & 0.53 & 4.32 & 1.00 & 0.11 \\
B/M & 23.0 & 20.3 & & 0.39 & 2.38 & 1.08 & 2.83 \\
6MR & 19.6 & 19.6 & & 0.18 & 1.74 & 0.98 & -1.28 \\
ER FY1 & 22.5 & 23.1 & & 0.34 & 3.66 & 0.96 & -2.72 \\
VMR & 20.3 & 19.5 & & 0.54 & 5.41 & 1.01 & 0.82 \\
\hline
\end{tabular}

Volatility is the annualized standard deviation of monthly returns. Regression results are based on regression of monthly returns of the winners or top portfolio on monthly EWI returns. $t(\alpha)$ is the $t$-value of $\alpha$, and $t(\beta-1)$ is the $t$-value of $\beta$ minus one.

Table 9: Size and Liquidity of Stock Selection Strategies

\begin{tabular}{llllll}
\hline \hline \multirow{2}{*}{ Strategy } & \multicolumn{2}{c}{ Market Cap. } & & \multicolumn{2}{c}{ Turnover Ratio } \\
\cline { 2 - 3 } \cline { 5 - 6 } E/P & Top & EWI & & Top & EWI \\
\hline B/M & 248 & 274 & & 2.03 & 2.01 \\
6MR & 177 & 274 & & 2.02 & 2.04 \\
ER FY1 & 335 & 272 & & 2.82 & 2.16 \\
VMR & 548 & 415 & & 3.33 & 3.15 \\
\hline
\end{tabular}

The table reports averages of monthly median values of the market capitalization (in millions of US\$) and turnover ratio for stocks in the winners portfolio and the universe of stocks. Turnover ratio is defined as the number of shares traded in each month divided by the total number of outstanding shares, expressed as percentage.

Table 10: Monthly Earnings Growth, P/E Growth and Earnings Revisions

\begin{tabular}{|c|c|c|c|c|c|c|}
\hline \multirow[b]{2}{*}{ Strategy } & \multicolumn{2}{|c|}{ EG } & \multicolumn{2}{|c|}{$\mathrm{P} / \mathrm{E}$} & \multicolumn{2}{|c|}{ ER } \\
\hline & $\bar{r}$ & $t(\bar{r})$ & $\bar{r}$ & $t(\bar{r})$ & $\bar{r}$ & $t(\bar{r})$ \\
\hline $\mathrm{E} / \mathrm{P}$ & -3.44 & -7.12 & 3.84 & 7.76 & -1.0 & -3.7 \\
\hline $\mathrm{B} / \mathrm{M}$ & -3.42 & -3.55 & 3.87 & 3.97 & -1.8 & -5.3 \\
\hline $6 \mathrm{MR}$ & 2.98 & 4.06 & -2.85 & -3.86 & 3.1 & 12.8 \\
\hline ER FY1 & 0.96 & 1.22 & -0.66 & -0.83 & 2.9 & 14.7 \\
\hline VMR & -1.47 & -2.95 & 1.98 & 3.86 & 2.8 & 11.4 \\
\hline
\end{tabular}

Growth rates of earnings and $\mathrm{P} / \mathrm{E}$ ratio, and earnings revisions are computed by averaging over the six winners portfolios that are held each month and the corresponding universes of stocks, and are expressed as percentages. The table reports the average difference between the winners portfolio and universe average over the first 36 months after portfolio formation $(\bar{r})$ and the corresponding $t$-statistic $(t(\bar{r}))$. 


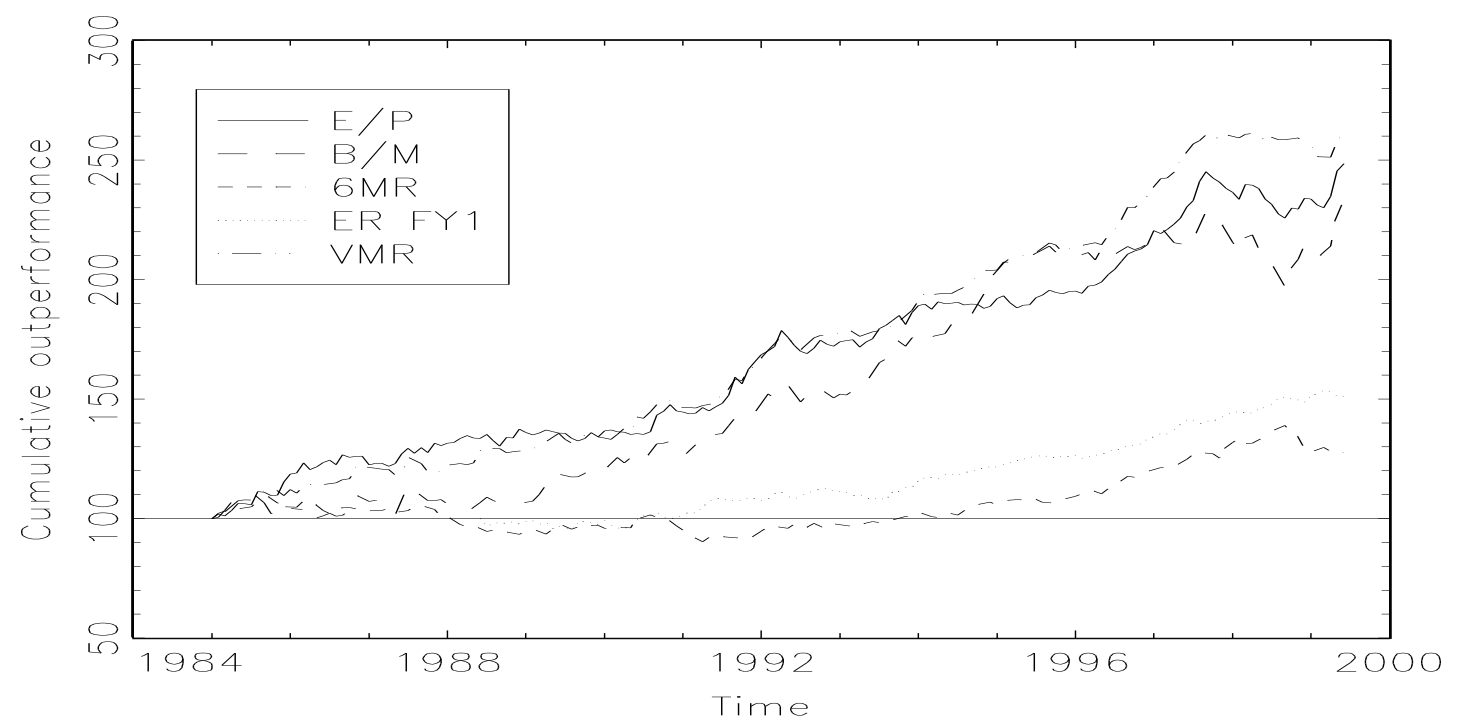

Figure 1: Cumulative outperformance of the top portfolio relative to the equally weighted index for strategies based on earnings-to-price (E/P), book-to-market $(\mathrm{B} / \mathrm{M})$, past 6-month return (6MR), past 3-month earnings revisions for the current fiscal year (ER FY1) and the total score on measures of value, momentum and revisions (VMR) (January 1985=100).

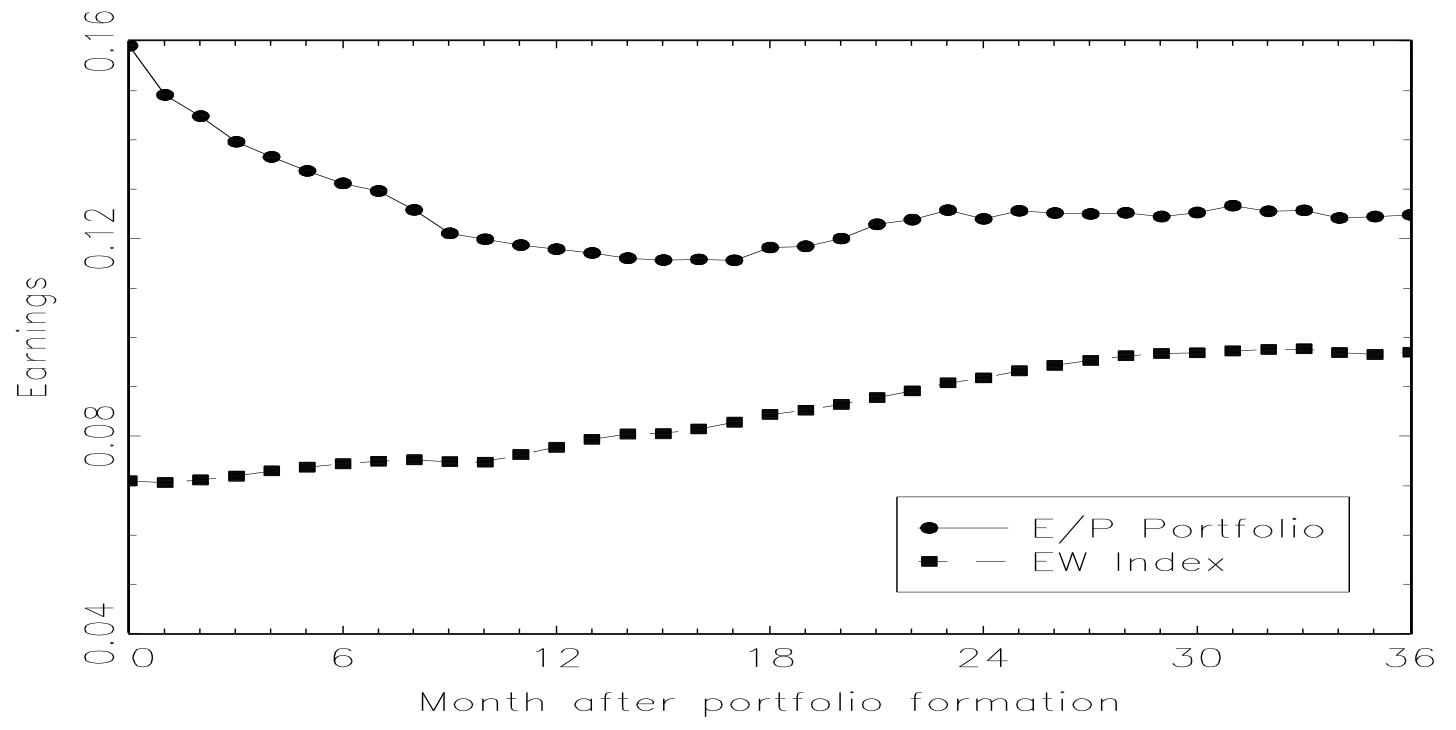

Figure 2: Earnings, expressed as percentage of initial investment, after portfolio formation for the winners portfolio of the E/P strategy and the equally weighted index of all stocks in the corresponding universe. 


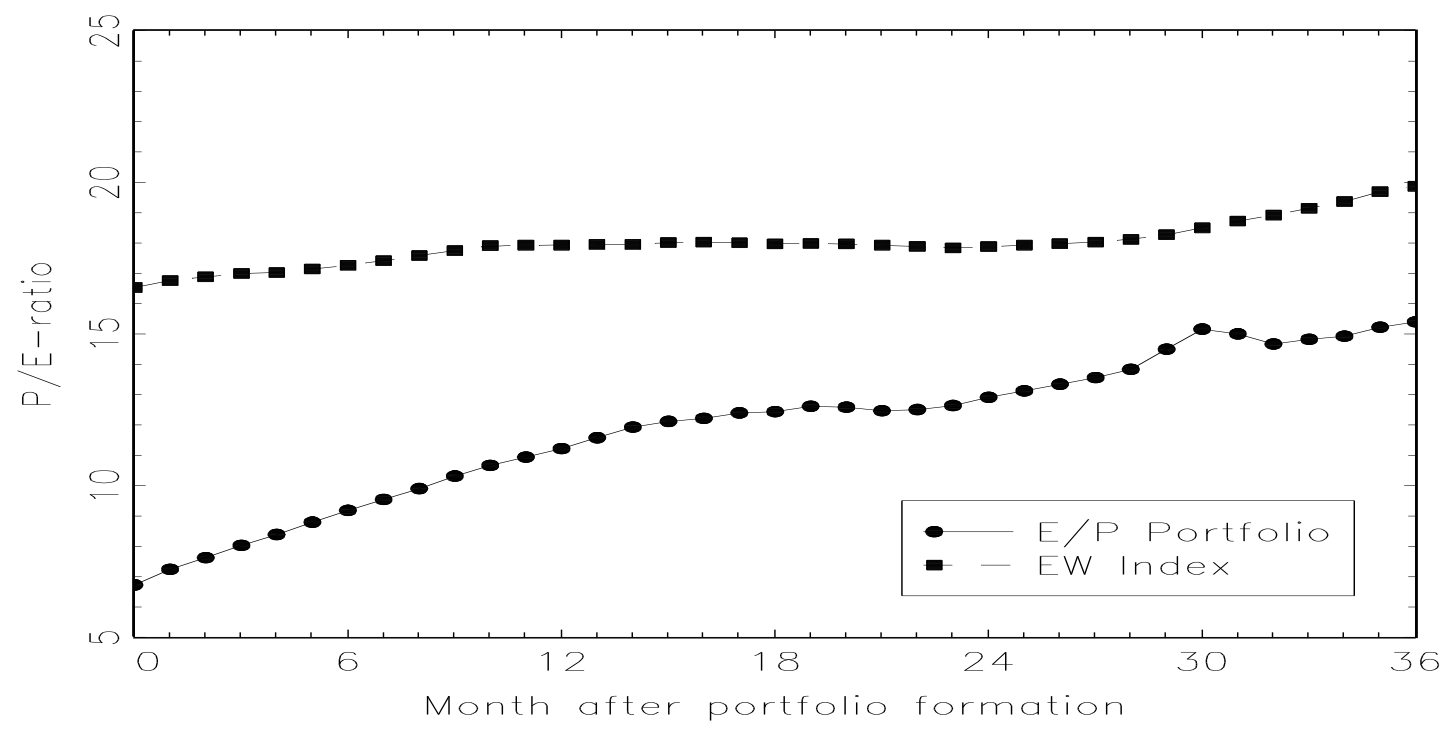

Figure 3: $\mathrm{P} /$ E-ratio after portfolio formation for the winners portfolio of the $\mathrm{E} / \mathrm{P}$ strategy and the equally weighted index of all stocks in the corresponding universe.

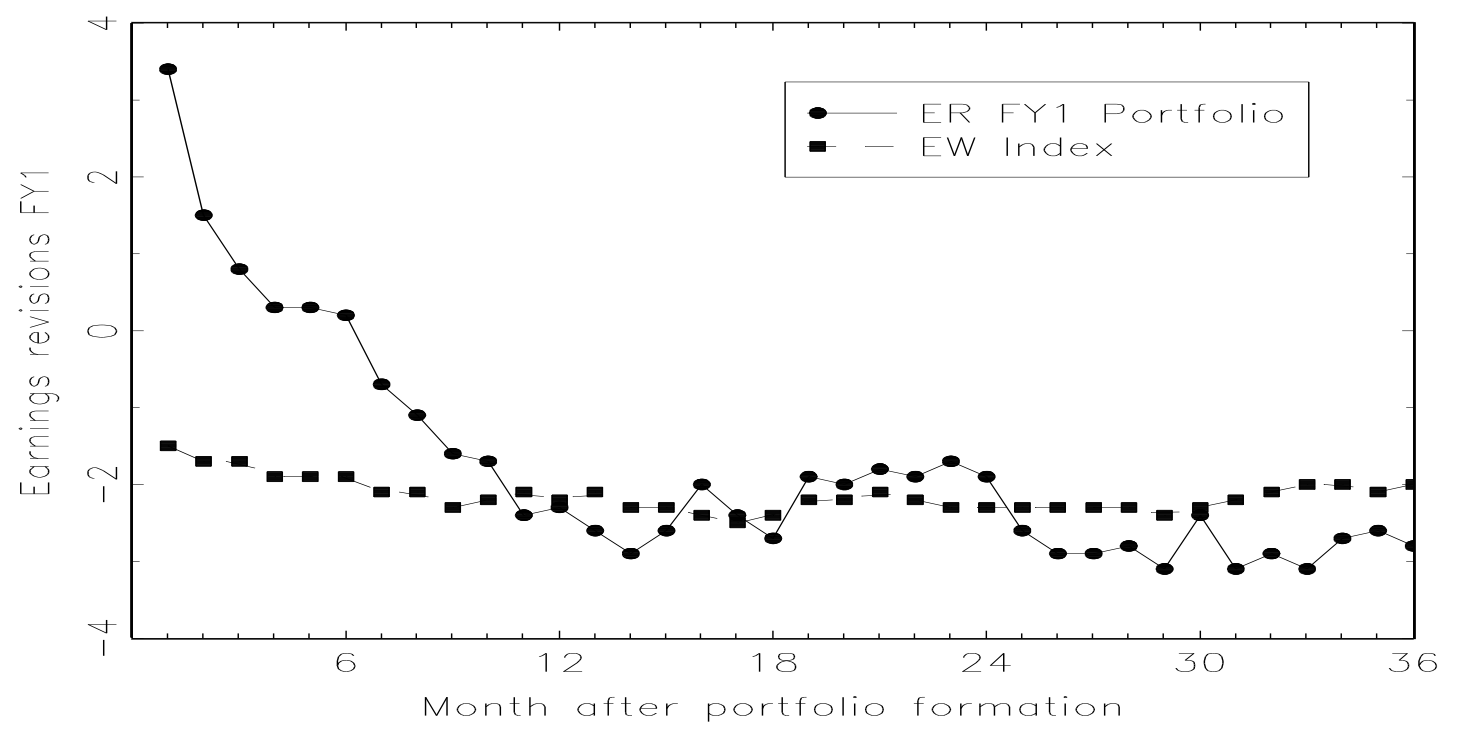

Figure 4: Monthly earnings revisions after portfolio formation for the winners portfolio of the ER FY1 strategy and the equally weighted index of all stocks in the corresponding universe, expressed as percentage. 